\title{
A Necessidade de se atentar aos lugares comuns da história urbana e social das cidades
}

\section{The Need to Pay Attention to the Common Places of Urban and Social History of Cities}

Philippe Arthur dos REIS*

Obra resenhada:

MANZONI, Francis. Mercados e feiras livres em São Paulo: 1867-1933. São Paulo: Edições Sesc São Paulo, 2019. 208p.

O livro Mercados e feiras livres em São Paulo (1867-1931), do historiador Francis Manzoni, lançado pela Edições Sesc em 2019, é fruto de sua dissertação de mestrado defendida na Universidade Estadual Paulista cinco anos antes. $\mathrm{O}$ autor apresenta à comunidade de historiadores e ao público geral o universo do abastecimento e da alimentação da capital paulista, em diálogo com a urbanização, o mundo do trabalho e os conflitos dos diferentes sujeitos que formaram a cidade, como negros, migrantes e estrangeiros. Tais agentes são compreendidos como os protagonistas de uma história feita por lavradores, carroceiros, carregadores, vendedores ambulantes, tropeiros e comerciantes que atuavam no ramo alimentício e de produtos de uso cotidiano pela população da cidade entre o final do século XIX e o começo do século XX. A obra

\footnotetext{
* https://orcid.org/0000-0003-0645-1091

Unicamp, Departamento de História

Rua Cora Coralina, 100, Barão Geraldo, 13083-872, Campinas, SP, Brasil philippearthur@hotmail.com
} 
destaca como os mercados públicos paulistanos, as feiras e o comércio ambulante tiveram um papel central no abastecimento e foram parte constitutiva do processo de urbanização que São Paulo experienciou a partir das últimas décadas do Oitocentos.

Como define o autor na introdução do livro, busca-se conduzir o leitor ao chamado "tempo do Brasil sem agrotóxicos", quando da construção do primeiro mercado da capital paulista, na Várzea do Carmo, em 1867, até a inauguração do Mercado Municipal de São Paulo, na rua da Cantareira, em 1933. Manzoni defende a necessidade de se analisar a história da cidade a partir das práticas cotidianas e dos modos de vida, da multiplicidade de trabalhos e lutas. Segundo o autor, essas perspectivas foram geralmente silenciadas diante da "imagem de uma São Paulo rica, moderna e europeizada, minimizando outros modos de viver, trabalhar e lutar que eram numericamente menos expressivos, mas que subsistiram no interior e no entorno da metrópole do café" (MANZONI, 2019, p. 12).

No primeiro capítulo, "O campo e a cidade: trabalho, práticas populares e políticas públicas", há a apresentação da fisionomia dos espaços de produção e abastecimento paulistanos, sobretudo chácaras que se localizavam ao redor da capital paulista, além dos projetos urbanos que auxiliaram no afastamento de tais áreas de cultivo. $\mathrm{O}$ segundo, "O comércio popular de alimentos na cidade: ruas, mercados, feiras de São Paulo", evidencia a organização e os usos de estabelecimentos alimentícios populares que auxiliaram na formação de grupos e territórios diferenciados, o que possibilitou a existência de múltiplos processos de resistência de trabalhadores pobres que buscavam a sua permanência em áreas valorizadas, a exemplo dos ambulantes nas ruas centrais. Por fim, em seu último capítulo, "Entre normas e exceções: o cotidiano dos comerciantes no abastecimento alimentício de São Paulo", Francis Manzoni confere destaque aos regulamentos e normas municipais que incidiam sobre esse grupo de agentes, como a atuação dos órgãos de fiscalização, em especial a Intendência de Polícia e Higiene. A tensão dos produtores e comerciantes com o poder público municipal se torna um dos grandes temas do capítulo, como o embate que contrapôs guardas-fiscais e 
alguns verdureiros do Mercado 25 de Março, em 1910. Os trabalhadores denunciaram os fiscais, alegando serem "perseguidos, maltratados e até agredidos fisicamente com chibatadas", e "lembraram ao poder público o episódio da Revolta da Chibata, que ocorria naquele mesmo novembro de 1910, no Rio de Janeiro" (MANZONI, 2019, p. 175-176).

A passagem anteriormente transcrita sinaliza para as formas de resistência da população trabalhadora da cidade diante da imposição de regras e da própria repressão a que eram submetidos. Dessa forma, há um implícito diálogo com obras de historiadores que analisaram o cotidiano do trabalho dos setores populares, como os de Maria Odila Leite da Silva Dias (1984) e Sidney Chalhoub (1986). A obra de Manzoni também estabelece conexão com as proposições de Edwald Palmer Thompson no campo da História Social e dos Estudos Culturais, bases que sustentam a proposta de conferir protagonismo aos seus agentes investigados. É a partir da leitura daqueles historiadores e outros intelectuais que investigaram as comunidades roceiras paulistas que o autor propõe aprofundar questões que considera terem sido tratadas de forma "generalizante e homogeneizadora", como nas obras de Antônio Cândido (1982) e Maria Sylvia de Carvalho Franco (1997). No caso do trabalho de Franco, por exemplo, Manzoni percebe a continuidade da reafirmação do isolamento e autossuficiência da vida dos trabalhadores "caipiras", visto que a socióloga não valoriza as iniciativas e atividades de cunho comercial, aspecto que foi observado pelo autor, mas que, provavelmente, pode ser a característica de uma sociedade em que os traços rurais já não possuem a mesma dimensão econômica como de Guaratinguetá, cidade de análise da autora.

O amplo conjunto de fontes que o historiador mobiliza confere ao leitor uma perspectiva que vai além da documentação oficial, como a legislação e os relatórios de intendentes e prefeitos, entrecruzados com livros de cronistas e memorialistas. O debate é enriquecido com o recurso às fotografias de autoria de Aurélio Becherini, Vincenzo Pastore, Guilherme Gaensly e Benedito Junqueira Duarte, além de mapas, aquarelas e plantas arquitetônicas que atestam a presença popular no comércio de rua, nos mercados e pequenos estabelecimentos comerciais que 
inundaram a cidade no começo do século XX. Compondo o rol iconográfico do livro, junto dele vem acompanhado um mapa dos mercados públicos e feiras livres da cidade existentes naquele tempo, identificados na Planta Geral da Cidade de São Paulo com indicações diversas, organizada pela Comissão Geográfica e Geológica, em 1914.

Ao conferir um olhar detido nos ofícios daqueles trabalhadores, Manzoni contribui para o debate sobre a diversidade de atividades que estavam envolvidas nos mercados e feiras livres da cidade, em um diálogo com recentes pesquisas que buscam conferir destaque à presença da população pobre e racializada. No caso mais específico da cidade de São Paulo, há de se considerar que sua mão de obra não se circunscreveu aos grupos imigrantes, como demonstrado em Nem tudo era italiano: São Paulo e pobreza (1890-1915), de Carlos José Ferreira dos Santos (1998), autor com o qual Manzoni dialoga.

Ao propor um diálogo da atuação desses trabalhadores conjuntamente ao processo de transformações que a capital paulista experienciou, o historiador encara seus agentes como um grupo que esteve alijado do processo de urbanização ali ocorrido, e seus ofícios serviriam como uma manifestação de resistência frente a tais transformações, chave interpretativa que pode induzir à uma compreensão dual ou passiva daquele grupo. Os pequenos comerciantes, carroceiros, ambulantes e, em geral, a população pobre, foram encarados em muitos dos primeiros escritos urbanos e de história urbana como "empecilhos" à modernização das cidades, o que não significa que não atuaram politicamente dos debates urbanos e da própria construção material de São Paulo, como demonstrado por Josianne Cerasoli (2004).

As elites locais também entram em cena no debate proposto por Manzoni, sobretudo no que toca à sua relação com as classes populares. Em algumas passagens, o autor encara as transformações da cidade como uma ação exclusiva e patrocinada por aqueles grupos que pensaram o contexto de reformas urbanas de São Paulo. Tal compreensão é análoga a outras leituras que entendem esses projetos como simples mecanismos de segregação socioespacial na busca incessante de afastamento da população pobre da porção central. Por exemplo, o autor cita que 
No contexto das reformas urbanas das décadas de 1890 a 1910, novas remodelações ocorreram: (...) antigas e pequenas moradias desapareceram e seus habitantes foram deslocados para outros pontos da cidade, quase sempre em regiões pantanosas e de várzea, onde se formavam os bairros populares: Brás, Mooca, Bom Retiro, Belenzinho, Barra Funda, Água Branca, Lapa, entre outros. (MANZONI, 2019, p. 37)

O trecho acima exemplifica a ideia comum e generalizante de entender a cidade de São Paulo do começo do século XX como um espaço "segregado", no qual a população pobre se instalava exclusivamente de um lado e a rica de outro, com espaços exclusivos e sem trânsito entre as duas camadas sociais, interpretação que ganhou notoriedade em estudos dos anos 1980 e 1990 como de Eva Blay (1985), Raquel Rolnik (1997) e Nabil Bonduki (1998). A tese de que os bairros paulistanos foram planejados para abrigar determinadas classes sociais já foi objeto de questionamento, em estudos mais recentes como o de Paulo Garcez Marins (2011) sobre os Campos Elíseos, e de Sheila Schnek (2016) sobre o Bixiga.

A impressão resultante da leitura da obra é de que a abordagem defendida por Manzoni se insere no debate acerca "das ideias fora do lugar", traduzida aqui pela implementação de ideias e projetos urbanos gestados fora do Brasil e que não levaram em consideração as particularidades do país, pois se buscava apenas atender os interesses das elites locais. A ideia de que muitos dos projetos não fossem "funcionais" ou "adequados" à realidade social brasileira, como as obras de modernização da cidade de São Paulo, talvez seja mais um tópico de oposição às proposições de Maria Sylvia de Carvalho Franco, visto que a autora é uma das que tece crítica à noção de "cópia". Logo, para Manzoni, as ações urbanísticas implementadas pelo poder público são interpretadas como um desejo das elites locais em se aproximar do "modelo [d] as grandes e 'civilizadas' cidades europeias” (MANZONI, 2019, p. 32), debate que ganhou fôlego nos últimos anos. ${ }^{1}$

1 Ver, por exemplo, o balanço escrito por Marisa Carpíntero e Josianne Cerasoli (2009) sobre a 
Em outro trecho, o autor pontua que "pretendendo 'redesenhar' a cidade, as elites cobram do poder público o direito de desapropriação por meio do qual poderiam deslocar os territórios de populares para áreas mais distantes", sobretudo aqueles que "resistiram em permanecer nas áreas centrais para as regiões menos valorizadas, próximas às linhas férreas, onde se instalavam as fábricas e a população operária" (MANZONI, 2019, p. 35-37). A ideia, que em muito se aproxima das interpretações problematizadas nas décadas de 1980 e 1990, também busca se alinhar a um debate contemporâneo que enxerga que uma parte desses trabalhadores pobres permaneceu ocupando com moradia e trabalho as áreas do centro da cidade, aspecto que poderia ser melhor explorado em suas colocações. Por vezes, as implementações urbanas da cidade são encaradas como projetos que tinham como único fim a segregação espacial da população pobre, e que lograram com esse objetivo, quando trata, por exemplo, do desmanche do Mercado São João, em 1916, em favor do alargamento da rua homônima. Essa também contou com a remoção dos "demais territórios populares, alguns deles de má fama, [que] foram demolidos e deram lugar a um elegante bulevar" (MANZONI, 2019, p. 96). Há de se considerar que muitos dos projetos urbanos, como da remodelação da avenida São João, se estenderam por muitos mais anos e nunca conseguiram de fato afastar a população pobre e marginalizada, visto que habitações populares, botequins e bordeis coexistiram, persistindo nos logradouros que passaram por transformações como a referida via.

O foco nas ações da elite paulistana, que buscou se afastar da população mais pobre por meio da implementação de projetos urbanos modernos, é também acompanhado de uma crítica ao papel que instituições sanitárias empreenderam para aqueles fins, como a atuação do Serviço Sanitário Municipal, e sobretudo da Seção de Polícia e Higiene. Com o crescimento das cidades, a questão sanitária se tornou um problema, e para conter o aumento dos casos de doenças e mesmo para

produção acadêmica que tomou a cidade como objeto da história e como as questões urbanas também passaram a ser um objeto dos historiadores. 
fluir o trânsito de suas vias, houve projetos de cidade em disputa, os quais poderiam ser aprofundados para tratar dos "antigos preconceitos da elite paulistana contra negros, mestiços, brancos pobres e roceiros" (MANZONI, 2019, p. 115).

O autor de Mercados e feiras livres em São Paulo também propõe uma análise em torno da composição étnica dos trabalhadores que investiga, pois tece crítica à noção reducionista e amplamente difundida de que o único grupo assalariado e com evidência na cidade foi o de imigrantes, lugar comum que pressupõe a existência de uma cidade não racializada. É de conhecimento da historiografia que grande parte da população que passou a residir em São Paulo a partir do último quartel do Oitocentos foi composta por imigrantes brancos e seus descendentes, o que auxiliou a forjar uma espécie de "tripé" da formação histórica paulistana, junto do papel que a ferrovia e a economia cafeeira desempenharam na economia da cidade. Logo, ao conferir atenção à população negra e mestiça da cidade, bem como das tensões e relações sociais que ela construiu com outros grupos pobres, Manzoni contribui na discussão acerca das oportunidades que determinados agentes possuíam em detrimento de outros, ainda que ambos fossem pobres.

Na obra, o imigrante pobre é observado como um grupo que possuiu maiores chances de ser incorporado ao mercado de trabalho diante da população local, como quando cita o fato de que a "autonomia dos roceiros de origem nacional começa a ser ameaçada pela concorrência estrangeira e pelo próprio desenvolvimento do capital" (MANZONI, 2019 , p. 60). De certa forma, a generalização da categoria "imigrante" poderia ser melhor explorada, visto que muitos dos que aportaram no estado de São Paulo provinham de lugares diferentes e possuíam ofícios e classes distintas, não sendo um grupo homogêneo, haja vista que a desconstrução de homogeneidades é um dos objetivos do autor.

Por fim, há de se considerar uma pequena confusão terminológica, quando o autor emprega a palavra "Prefeitura", e que possivelmente gostaria de se referir à "municipalidade", quando cita o Código de Posturas de 1886, e o Regulamento para as Praças de Mercado, de 1896 
(MANZONI, 2019, p. 134-135), visto que o cargo de prefeito só passa a existir no ano de 1899.

O livro de Francis Manzoni é uma contribuição original no que tange aos estudos sobre a classe trabalhadora de São Paulo, por estimular o debate acerca da presença desses grupos diante da "modernização" que a cidade experienciou na passagem do século XIX para o XX. Suas ricas fontes documentais, combinadas à busca da superação de enquadramentos construídos anteriormente, poderiam ser acompanhadas de um debate teórico em torno da gestação e dos usos dos projetos urbanos nas cidades, tema que avançou consideravelmente no cenário historiográfico contemporâneo e possibilita demonstrar a potencialidade de atuação dos agentes da history from bellow na história da cidade de São Paulo.

\section{Agradecimentos}

Texto produzido com apoio da Fundação de Amparo à Pesquisa do Estado de São Paulo (Processo FAPESP no 2018/17990-7), a quem o autor agradece.

\section{REFERÊNCIAS BIBLIOGRÁFICAS}

BLAY, Eva Alterman. Eu não tenho onde morar: vilas operárias na cidade de São Paulo. São Paulo: Nobel, 1985.

BONDUKI, Nabil Georges. Origens da habitação social no Brasil: arquitetura moderna, lei do inquilinato e difusão da casa própria. São Paulo: Estação Liberdade, 1998.

CANDIDO, Antonio. Os Parceiros do Rio Bonito. São Paulo: Duas Cidades, 1982.

CARPÍNTERO, Marisa Varanda; CERASOLI, Josianne Francia. A Cidade como história. História: Questões \& Debates, n. 50, p. 61-101, 2009.

CERASOLI, Josianne Francia. Modernização no plural: obras públicas, tensões sociais e cidadania em São Paulo na passagem do século XIX para o XX. Tese (Doutorado em História) - Universidade Estadual de Campinas, Campinas, 2004. 
CHALHOUB, Sidney. Trabalho, lar e botequim: o cotidiano dos trabalhadores no Rio de Janeiro da Belle Époque. São Paulo: Brasiliense, 1986.

DIAS, Maria Odila Leite da Silva. Quotidiano e poder em São Paulo no século XIX. São Paulo: Brasiliense, 1984.

FRANCO, Maria Sylvia de Carvalho. Homens livres na ordem escravocrata. São Paulo: Editora da Unesp, 1997.

MARINS, Paulo César Garcez. Um Lugar para as elites: os Campos Elíseos de Glette e Nothmann no imaginário urbano de São Paulo. In: LANNA, Ana Lúcia Duarte Lanna et al. (org.). São Paulo, os estrangeiros e a construção das cidades. São Paulo: Alameda, 2011. p. 209-244.

ROLNIK, Raquel. A Cidade e a lei: legislação, política urbana e territórios na cidade de São Paulo. São Paulo: Studio Nobel/Fapesp, 1997.

SANTOS, Carlos José Ferreira dos Santos. Nem tudo era italiano: São Paulo e pobreza (1890-1915). São Paulo: Annablume/Fapesp, 1998.

SCHNEK, Sheila. Bexiga: cotidiano e trabalho em suas interfaces com a cidade (1906-1931). Tese (Doutorado em Arquitetura e Urbanismo) Universidade de São Paulo: São Paulo, 2016. 